\title{
Identidade indígena: visões sobre o índio em Maíra, de Darcy Ribeiro
}

\section{Indigenous identity: views about the indian on Maíra, by Darcy Ribeiro}

\author{
Maíra Contrucci JAMEL* \\ UFRJ
}

\section{Monica do Nascimento FIGUEIREDO** \\ UFRJ}

Resumo: A figura do índio sempre esteve presente ao longo do desenvolvimento da literatura brasileira. Desde os registros das crônicas portuguesas, quando ainda não tínhamos uma literatura consolidada, até atingir um papel importante no século XIX, como elemento essencial do projeto estético-ideológico romântico, que buscava constituir uma nacionalidade brasileira. Este trabalho pretende analisar a representação literária do índio no romance Maíra, de Darcy Ribeiro (1976), a fim de tecer considerações sobre a representação do índio nas produções literárias do século XX. Para tanto, será feito um breve panorama das representações do índio na literatura brasileira e destacaremos a importância da voz narrativa na construção dessa imagem. Se a representação literária do indígena está diretamente relacionada com a imagem que a sociedade desenvolveu do índio, faz-se necessário abordar o contexto histórico de produção da obra, assim como destacar a voz autoral de um escritor-antropólogo como Darcy Ribeiro. Por fim, será abordada a questão da nacionalidade brasileira, a fim de articular o tema do índio com outro que lhe foi correlato no desenvolvimento de nossa literatura. Com isso, pretende-se analisar a imagem do índio caído, elemento recorrente nas narrativas que abordam a figura indígena no século XX.

Palavras-chave: Identidade Indígena. Darcy Ribeiro. Maíra

\begin{abstract}
The figure of the Indian was present thru the development of Brazilian literature. Since the Portuguese chronicles, before a consolidated Brazilian literature, until an important role in the nineteenth century, as an essential element of the Romantic aesthetic- ideological project that sought a Brazilian nationality. This paper discusses the literary representation of the Indian in the novel Maíra in order to make considerations about the representation of the Indian on the twentieth century literary productions. For this, it will be presented a brief overview of the representations of the Indian in Brazilian literature, highlighting the importance of narrative voice on the consolidation of its image. If the literary representation of the indigenous is directly related to the image that society has developed about the Indians, it is necessary consider the historical context of the novel, as well as the point of view of the writer - the anthropologist Darcy Ribeiro (1976). Finally, it will be analyze the issue of Brazilian nationality, also related to the Indian figure in the development of our literature. Therefore, we intend to analyze the image of
\end{abstract}

\author{
* Mestre em \\ Literatura Portuguesa. \\ mairacj@gmail.com \\ (Bolsista FAPERJ \\ Aluno Nota 10 - nível \\ Doutorado) \\ ** Doutora em Letras. \\ mnfigueiredo@ \\ hotmail.com
}


the fallen Indian, an recurring element in narratives that deal with the Indian figure in the twentieth century.

Keywords: Indigenous Identity. Darcy Ribeiro. Maíra

É como ele diz: "ser brasileiro, congolês, ou mairum, não é a mesma coisa? Você é mairum como eu podia ser congolês”. Mas não é assim. Ele não diz: você é mairum como eu sou genovês, como nossos irmãos da Ordem são italianos, alemães, brasileiros. Diz que eu sou mairum (e sou) tal como aquele congolês a quem ele se refere tem a desgraça de ser de certa tribo do Congo. Ele não sabe, mas eu sei bem que, no dia em que houver uma nação congolesa mesmo, os mairuns de lá continuarão a ser mairuns, quer dizer, não-congoleses: ninguém!

Isaías/Avá

Maíra, de Darcy Ribeiro (1976)

\section{O Índio como tema: breve panorama da figura do índio na literatura brasileira}

O cerne desse artigo se constrói através de uma crítica temática sobre a figura indígena nos moldes defendidos por Leyla Perrone-Moisés. Em seu livro Falência da Crítica (1973), ela argumenta que o tema pode ser utilizado como guia de leitura de duas formas diferentes:

O tema de uma obra literária apresenta pois um duplo aspecto: ele pode ser considerado como fonte, ponto de partida, ou como formador e modalizador das estruturas da obra. Assim, quando procuramos o tema de uma obra, podemos chegar a seu ponto de partida- as imagens obsessivas de um autor ou de uma época, ou ao seu ponto de chegada- o modo como o tema se apresenta numa obra particular, como ele a estrutura e a modula, como, enfim, ele ajuda a fazê-la. O primeiro caminho nos afasta da obra, considerada então como transparente, como meio de chegar a outra coisa. O segundo nos permite uma crítica imanente, na qual o elemento referencial pode ajudar à compreensão da estrutura da obra e de seu funcionamento. (PERRONE-MOISÉS, 1973, p. 105)

Não pretendemos considerar a obra "transparente", como apenas um meio de se chegar a uma interpretação que coloque o texto literário em segundo plano. Por conseguinte, descartamos o primeiro caminho apresentado por Leyla Perrone-Moisés (1973) e elegemos o segundo como um meio de contribuir para a compreensão do corpo textual. Concordamos com a crítica quando ela afirma que "O tema não preexiste a obra, ele se configura à medida que a obra se faz.” Entendido dessa forma, o tema não reduz a interpretação literária a um único aspecto. Pelo contrário, amplia as possibilidades de leitura de uma obra e é dessa forma que buscaremos compreender o índio ao longo da narrativa de Maíra. 
Claro está que tratar do tema do índio foi uma escolha preexistente à obra, como nos conta o próprio Darcy Ribeiro (1997) ao afirmar que Maíra é “um romance de dor e gozo de ser índio” (1997, p. 512) Mas o desenvolvimento do tema ao longo da estrutura narrativa é com o que iremos nos preocupar nesse trabalho.

Inicialmente, podemos destacar com relação à abordagem do índio no romance de Darcy Ribeiro uma representação distinta que dele era feita em outros períodos da literatura brasileira. Em Maíra, além de toda uma grande explanação dos hábitos e cultura indígena, temos o índio não estereotipado, mas problematizado. Isaías, personagem principal do romance, é um homem perturbado por questões interiores e subjetivas na tentativa de entender o que é ser índio na sociedade brasileira do final do século XX.

Ao pensarmos na figura indígena na literatura brasileira, a tendência é uma referência ao século XIX, em que o Romantismo teve como uma de suas principais características o indianismo. Contudo, ainda que neste período a figura indígena tenha ganhado destaque por estar ligada a um programa estético-ideológico específico, atrelado à formação da pátria e à valorização do nacional, não é correto afirmar que as representações ficcionais relevantes sobre o índio estejam restritas ao período do romantismo.

Para expressar o que viram de novo nessas terras, os cronistas portugueses do século XVI se referiam ao índio com admiração e surpresa, destacando aspectos como a vida em coletividade, a suposta ausência da religião e a nudez sem vergonha.

A impressão dos portugueses era de que o índio era uma "página em branco”, vivendo em uma sociedade sem crédulos, em quem "imprimir-se-á com ligeireza neles qualquer cunho, que lhes quiserem dar” (CAMINHA apud CUNHA, 2012, p. 31). No contexto do início do processo de catequese nos séculos XVI e XVII, destaca-se a literatura produzida pelo Padre José de Anchieta, que utilizou o teatro como um meio didático para afastar os índios de sua própria cultura. Nos autos produzidos por Anchieta cabe ao índio o papel do demônio. Seus hábitos e crenças são verdadeiros pecados que resultarão na punição divina, para qual a única salvação é a conversão à fé cristã. A mesma visão acerca do elemento indígena é aplicada às suas poesias.

A primeira obra literária brasileira, Prosopopeia, de Bento Teixeira, reserva ao índio o papel de vilão, que deveria ser domesticado para que se estabelecesse o heroísmo do colono português. Nas palavras de Alcmeno Bastos (2011):

Em resumo, assim estigmatizado, obstáculo a ser varrido do caminho do herói, pintado com cores bem diversas da impressão favorável que dele teve Caminha e, como vimos, todos os cronistas que conheceram seu habitat quase edênico, livre, digno e insubmisso, estreia o índio na literatura brasileira. (2011, p.66) 
No século XVIII, destaca-se O Uraguai, de Basílio da Gama, poema que estabelece uma crítica à ação dos jesuítas no Brasil, encarados como enganadores dos índios. Há, nesse poema, uma postura discursiva do narrador mais positiva em relação ao índio, tanto que segundo Antonio Cândido "O Uraguai se tornou um dos momentos-chave da nossa literatura, descrevendo o encontro de culturas (europeia e ameríndia), que inspiraria o Romantismo indianista.” (2008, p. 109)

Ainda naquele século, há outro viés de representação da figura indígena em Caramuru, obra do frei Santa Rita Durão, em que segundo Alfredo Bosi (1994) “o índio é objeto de colonização e catequese, perde sua autenticidade étnica e regride ao marco zero do espanto (quando antropófago), ou a exemplo de edificação (quando religioso).” (BOSI, 1994, p.68)

É no século XIX que a postura dos escritores brasileiros para com a figura indígena se transforma definitivamente. A tentativa de dar ao índio um lugar na recente criação da identidade nacional fez do romantismo o "movimento literário de intencional valorização da figura do índio" (BASTOS, 2011, p. 13).

Os dois escritores românticos que se destacam com relação ao indianismo são Gonçalves Dias e José de Alencar. O indianismo fez parte de um programa estético-ideológico que associado à busca de uma nacionalidade brasileira permeou a representação ficcional do índio nas obras dos escritores românticos.

De uma maneira geral, encontra-se em Alencar e Gonçalves Dias um índio guerreiro e idealizado, com atitudes guiadas pela retidão moral e obediência a princípios éticos. Dias transforma o índio em eu-lírico em poemas como Marabá, Leito de Folhas Verdes e I-Juca Pirama. Enquanto a prosa de Alencar expressa a possibilidade da aproximação cordial entre brancos e índios, a poesia de Gonçalves Dias é avessa a esse convívio, destacando aspectos negativos desse contato.

É interessante ressaltar que ambos os autores embasaram suas escritas em estudos etnográficos, chegando a atribuir diversas notas explicativas a fim de esclarecer o leitor acerca do universo indígena. Vemos nessa preocupação, além do cuidado com alcance do texto, a tentativa de legitimar a representação ficcional construída em suas obras. A construção de Maíra também foi embasada em estudos etnográficos de Darcy Ribeiro e veremos mais adiante como isso se reflete na obra aqui estudada.

De forma geral, o índio é tratado nos textos românticos de forma grandiosa a fim de se equiparar ao colonizador, possuindo qualidades que o tornam o símbolo perfeito da pátria em construção. Posteriormente, durante o Modernismo, movimento literário que também possui como característica o nacionalismo, as qualidades do índio o tornam superior ao estrangeiro. 
O Modernismo transforma a miscigenação do povo brasileiro no seu bem de maior valor. No Martim Cererê, de Cassiano Ricardo, o brasileiro surge da mistura de portugueses, negros e índios e as poesias são estabelecidas a partir de uma lenda indígena. Macunaíma é o herói sem caráter e identidade, fruto de um povo de origem plural, que herda suas qualidades, como a esperteza, e também seus defeitos, como preguiça e devassidão. Antonio Cândido afirma que o interesse dos modernistas pelo índio faz parte de um movimento neoindianista que procura acentuar “aspectos autênticos da vida do índio, encarando-o não como gentil-homem embrionário, mas como primitivo, cujo interesse residia precisamente no que trouxesse de diferente, contraditório em relação à cultura europeia.” (2006, p.33)

Esse breve resumo sobre as visões do índio em nossa literatura não pretendeu realizar um panorama completo, mas sim aspectos relevantes sobre como a figura indígena foi abordada pela literatura brasileira ao longo dos anos, o que servirá de embasamento para a análise do romance Maíra. Em narrativas da segunda metade do século XX, encontraremos a figura do índio caído, afastado de suas culturas e tradições e que muitas vezes serve de base para a reflexão do Brasil contemporâneo.

\section{O Índio Caído: Visões sobre o elemento indígena}

Maíra é um romance publicado em 1976, que levou muitos anos para ser concluído. Darcy Ribeiro iniciou a obra enquanto estava no exílio no Uruguai, entre 1964 e 1968. Posteriormente, em 1969, no período em que esteve preso, continuou a trabalhar na narrativa, tendo a concluído apenas em 1974-1975, quando se recuperava de uma cirurgia para tratar de câncer.

A narrativa expressa o ponto de vista de diversos personagens, mas mantém em todas elas uma descrição da história, das crenças e dos costumes do povo mairum. A história acompanha a trajetória do índio Avá, que deixou sua tribo ainda criança para viver em um seminário na Europa. No “mundo dos brancos”, ele passa a se chamar Isaías, contudo, mesmo a longa convivência e o novo nome não foram capazes de fazer com que ele se sentisse realmente parte desse ambiente.

Isaías/Avá decide voltar à sua tribo e no caminho encontra Alma, jovem que levava uma vida permeada de drogas e sexo e vê na convivência com os índios uma possibilidade de se redimir. Assim sendo, os dois, com expectativas diferentes, partem juntos para a aldeia mairum.

Iniciando com um tom de mistério, a história começa com a descoberta de um corpo de uma mulher que acabara de dar à luz gêmeos, próximo à aldeia mairum. Mais tarde, descobrimos que a mulher morta é Alma. Começam as investigações desse caso, o que levará o major 
Nonato à reserva indígena. Além do oficial, também estão presentes Juca, um comerciante filho de índio com branco; funcionários da FUNAI; e missionários estrangeiros. Todos eles demonstram visões distintas sobre o índio, que se refletem em suas atitudes e falas ao longo da narrativa.

O cerne da narrativa é o conflito existencial de Isaías/Avá que procura se reintegrar à tribo indígena que deixou ainda criança para se tornar um sacerdote. Sua partida foi encarada de forma positiva pela tribo, pois ele iria “aprender com os padres a sabedoria dos caraíbas” (Maíra', p. 69). Porque nunca se sentiu um membro efetivo da sociedade clerical, decide "voltar ao convívio da minha gente e com a ajuda deles me lavar desse óleo de civilização e cristandade que me impregnou até o fundo.” ( $M$, p.174) No entanto, Isaías/Avá descobrirá que ter transitado entre os dois mundos, o indígena e o dos brancos, não garantirá sua adaptação a ambos. Ao contrário, ele se sente não pertencendo plenamente a lugar algum. Sua dualidade está até mesmo na prece que faz ao Deus cristão pedindo que conseguisse ser um pleno mairum, como podemos ver no seguinte trecho: “Que eu possa ser um entre todos. Indistinguível. Indiferenciável. Inconfundível. Um índio mairum dentro do povo mairum”. ( $M$, p. 109)

O conflito interno de Isaías/Avá está, de certa forma, presente em toda narrativa pela postura discursiva do narrador. Toda a história é desenvolvida através de monólogos dos personagens, mas a ideia que perpassa toda a obra é de que não existe conciliação possível entre índios e brancos. Dessa forma, Isaías/ Avá nunca poderia se adaptar ao mundo branco apenas por ser índio e não é capaz de harmonizar-se novamente com os mairuns, por ter vivido tanto tempo em meio aos brancos.

A incapacidade de se ver integrado a uma sociedade é o principal motivo das angústias internas de Isaías/Avá, como vemos em suas palavras: "Ser igual, apesar de todas as diferenças possíveis, graças a uma identidade essencial, é a isto que aspiro. Ralo minha cabeça de tanto pensar nisso.” ( $M$, p.32)

O que agrava ainda mais a situação de Isaías/Avá é o papel que lhe cabe dentro da tribo mairum. A aldeia é formada de vários clãs, cujos membros possuem uma função social específica. Isaías/Avá faz parte da casa dos jaguares, que fornece o chefe da guerra, o tuxaua, enquanto o chefe espiritual provém de outra tribo e se intitula aroé. Pela tradição, Isaías/Avá deveria ser o líder guerreiro dos mairuns, mas ele se identifica muito mais com a função de aroé do que com a que lhe cabe, a de tuxaua. Dessa forma, pode-se perceber que esse aspecto o distancia ainda mais do índio identificado com os valores e costumes de sua tribo, que vivia de acordo com um código de conduta, cantado pela literatura brasileira no século XIX.

A visão idealizada sobre o elemento indígena será adotada pela personagem Alma. Para ela, a aldeia indígena seria o lugar perfeito para

\author{
${ }^{1}$ A edição aqui \\ utilizada é: \\ Rio de Janeiro: \\ Civilização \\ Brasileira, 1976. \\ Para as citações \\ do texto, utilizarei \\ $M$, seguido do \\ número da página.
}


exercer trabalho de caridade e se redimir de seus pecados. No seguinte trecho, vemos como ela idealiza a vida na comunidade dos mairuns:

Pra mim esses mairuns já fizeram a revolução-em-liberdade. Não há ricos, nem pobres; quando a natureza está sovina, todos emagrecem; quando está dadivosa todos engordam.Ninguém explora ninguém. Ninguém manda em ninguém. Não tem preço essa liberdade de trabalhar ou folgar ao gosto de cada um. Depois, a vida é variada, ninguém é burro, nem metido a besta. Pra mim a Terra sem Males está aqui mesmo, agora. Nem brigar eles brigam. Só homem e mulher na fúria momentânea das ciumeiras. Deixa essa gente em paz, Isaías. Não complique as coisas, rapaz. (M, p. 269)

A descrição que Alma faz da tribo mairum é a de um lugar edênico e harmônico, em que a propriedade material e a cobiça não ditam as regras de funcionamento da sociedade. Essa visão vai ao encontro da percepção que alguns cronistas do século XVI, como Jean de Léry, Padre Manuel da Nobrega e Gabriel Soares de Souza, tiveram do índio. Esse último chega a afirmar, em seu Tratado Descritivo do Brasil (1587), que o desprendimento dos índios é tamanho que os tupinambás têm uma condição muito boa para frades franciscanos.

É a essa "terra sem males" que Alma aspira se integrar, chegando a se incomodar por ter a pele branca e não possuir um rosto mairum. Para ela, o mundo ocidental é o verdadeiro lugar selvagem: "Doentes somos nós. Doentes de indecência, de repressão ao humano, de repulsa ao que é natural. Somos abomináveis.” ( $M$, p. 243)

Apesar de adaptada à tribo, ela não se integra totalmente, assim como Isaías/Avá. Ele por estar dividido em suas angústias e ela por não ter nascido com um lugar marcado na tribo. A diferença principal entre os dois é que Alma poderia retornar ao mundo dos caraíbas e lá viver integrada, já Isaías/Avá não tem essa possibilidade.

Não é só por suas dúvidas e seus questionamentos existenciais que Isaías/Avá difere do índio de fortes crenças étnicas cantado por Gonçalves Dias e José de Alencar. Seu aspecto físico é oposto ao traço que havia despertado a atenção dos cronistas e jesuítas dos séculos XVI e XVII por transparecer saúde, robustez e beleza.

Alma se espanta ao conhecer Isaías/Avá e afirma: “Ele é triste, feio e triste, coitado. Nunca pensaria que fosse índio. Nem imaginava um índio assim franzino.” ( $M$, p.140) Seu espanto quando ao aspecto físico de Isaías é partilhado pelo major do exército que no seu relatório sobre o crime ressalta: "É um tipinho raquítico, caquético, justo o oposto da imagem que dele eu formava, pensando nos índios de verdade.” ( $M$, p. 182)

Ao afirmar que Isaías/Avá não parece um “índio de verdade”, o major deixa transparecer uma imagem consagrada no ideário popular brasileiro do índio representado na literatura romântica. Além de franzino, o que 
salta aos olhos de Alma é o fato de Isaías ser triste, como se o índio vivesse em um mundo do qual a tristeza não fizesse parte, o que corrobora a visão idealizada que ela tem da vida indígena.

É interessante notar a semelhança que o relatório produzido pelo major Nonato tem com as crônicas dos viajantes portugueses. Há uma descrição do aspecto físico dos índios e um questionamento sobre como se integrariam à civilização, como podemos ver na passagem a seguir:

$\mathrm{O}$ aspecto geral dos índios é bom, bons dentes, exceto alguns banguelas. Boa pele, limpa de sinais de doenças, exceto bexigas em alguns. Uns quantos rapagões daqui dariam excelentes recrutas. (...) Eles jamais se integrarão nos usos e costumes da civilização. (... ) Como são pidões esses pais-da-pátria. Não viria daí algo do caráter nacional? (p.229/230)

Nesse trecho também se destaca a ideia de que o caráter indígena está diretamente associado à identidade brasileira e que uma característica negativa da atual geração pode ser herança direta deles.

\section{Conciliação impossível: A Postura Discursiva do Narrador}

A postura discursiva do narrador revela uma crítica ao modo de funcionamento da FUNAI (Fundação Nacional do Índio). Darcy Ribeiro, já afastado do SPI (Serviço de Proteção ao Índio), fez parte do grupo de antropólogos que no final dos anos 50 militava por uma política indigenista diferente da então adotada, que pudesse mediar as relações entre os povos indígenas e o estado brasileiro.

As políticas indigenistas ao longo da história do Brasil não costumavam abordar o ponto de vista do índio, eram baseadas na necessidade do colonizador ou do governo estabelecido. Manuela Carneiro da Cunha (2012) afirma que, no século XIX, a questão indígena deixou de ser uma questão de mão de obra para se tornar uma questão de terras a fim de "mesquinhamente se apoderar das terras dos aldeamentos”. (CUNHA, 2012, p. 56) A historiadora destaca que a prática de concentração de grupos indígenas atendia a interesses exclusivamente do governo, que podia destinar terras antes ocupadas por índios a negócios econômicos, como a prática agrícola. Dessa forma, aldeias inimigas foram agrupadas num mesmo território, como o episódio em que os "índios de Minas Gerais foram entregues ao presidente da província do Espírito Santo para serem levados ao Aldeamento Imperial Affonsino, já existente. (7/1/1856)” (CUNHA, 2012, p.76) Esse fato mostra o total desrespeito às idiossincrasias das tribos indígenas e reforça a ideia de que a política indigenista não era voltada para os índios.

A postura do narrador em Maíra toma partido contra o processo civilizatório, estabelecendo uma crítica clara ao funcionamento da FUNAI. Na segunda metade do século XX, o órgão era subordinado ao Ministério 
do Interior, responsável pela política de desenvolvimento do país, que funcionou de forma predatória e via o índio como um "empecilho para o desenvolvimento". (CUNHA, 2012, p. 100)

Em Maíra, podemos ver esse posicionamento no discurso de Juca, um comerciante filho de um homem branco com uma índia mairum. Sua mãe era da casa dos onças, por isso ele acredita que com o sumiço de Isaías/ Avá tem direito de reivindicar para si o posto de tuxaua da tribo. Contudo, com a atual situação dos índios, ele pensa que isso não vale a pena e diz:

Não quero saber disso não. Sobretudo, agora, que os índios minguaram tanto e que é a FUNAI quem decide tudo lá em Brasília. Tuxaua já não vale nada. Posição boa mesmo, hoje em dia, é a de Agente de Posto, que nem seu Elias: ganha salário do governo todo mês e não precisa fazer nada. Nem querem que ele faça, como diz o fresco do meu compadre: não posso, não devo interferir nos costumes da tribo. Mas os mairuns estão se acabando. Não dou dez anos para acabarem de vez, sem deixar rastro. ( $M$, p.148)

O personagem que administra o posto da FUNAI responsável pela aldeia mairum, Elias, é descrito como um fazendeiro, que tem um "rebanho" de índios ao seu dispor. Suas falas revelam uma postura diferente daquela esperada de um agente do órgão que deveria proteger a cultura indígena. Em conversa com o major do exército, Nonato, o funcionário do posto da FUNAI afirma: "Não podemos contar com os índios para qualquer trabalho regular; apareceriam um dia e faltariam três.” ( $M$, p. 95)

A ideia de que a integração e conciliação entre mundo civilizado e tribos indígenas é impossível permeia toda a narrativa de Maíra. Ela está presente nos pensamentos que angustiam Isaías/Avá, como na seguinte frase: "Minha aldeia não é parte de coisa nenhuma. É um povo em si, quer dizer, uma tribo com sua linguinha, sua religiãozinha, seus costumezinhos destinados a desaparecer" $(M$, p. 61)

A forma predatória como a expansão civilizatória foi estabelecida no Brasil pode ser considerada uma das grandes críticas do romance. Nesse processo, o elemento indígena foi considerado um obstáculo a ser superado, como vemos na fala de Isaías/Avá: "Peço é que a civilização ande mais devagar(...) Eu bem sei que nós, os mairuns, só existimos porque os brasileiros nunca se interessaram, de fato, pelo Iparanã. No dia em que se interessarem, se acabou mairum.” ( $M$, p.174-175). Outro aspecto interessante a ser destacado nessa frase é a diferenciação que a personagem faz entre brasileiros e índios, reafirmando a distância que os separa, como se os índios não fossem cidadãos brasileiros.

Em O Povo Brasileiro - A Formação e o Sentido do Brasil, Darcy Ribeiro (1995) afirma que a população indígena brasileira foi amplamente exterminada, não só através de verdadeiros genocídios, mas também de largo processo de etnocídio. Segundo o antropólogo, enquanto o genocídio 
se deu por "guerras de extermínio, do desgaste no trabalho escravo e da virulência das novas enfermidades”(1995, p.144), o etnocídio foi igualmente dizimador e atuou através da “desmoralização pela catequese; da pressão dos fazendeiros que iam se apropriando de suas terras; do fracasso de suas próprias tentativas de encontrar um lugar e um papel no mundo dos 'brancos”” (1995, p.144)

Em Maíra, as "tentativas de encontrar um lugar e papel no mundo dos brancos”, ressaltadas em O Povo Brasileiro, são avaliadas de maneira pessimista por Isaías/Avá. A reação do índio, diante da dominação branca, aconteceu da seguinte forma: "No princípio todos queriam ser Caraíbas. Mais tarde, cada nova geração queria evadir da tribo para a vida com os brancos. Afinal, aprendemos que não há lugar para nós no mundo caraíba, senão lugares que nem bichos suportariam”. ( $M$, p. 189-191) Mais uma vez, é reafirmada a ideia de que a conciliação das culturas é inviável. E o processo de integração seria na verdade um modo de subjulgar os hábitos e costumes do índio, que nunca teria um lugar de respeito em meio a cultura ocidental.

Há de se destacar também sobre a postura discursiva do narrador a faceta através da qual são articuladas as perceptivas antropológicas, etnológicas e políticas ao longo dessa narrativa. Em estudo sobre a violência e o mal causado pelo processo civilizatório em Maíra, Sandra Martins Farias (2008) afirma que essa é "uma obra dialógica e densa - no sentido criado e descrito por Clifford Geertz” (FARIAS, 2008, p. 4). Segundo a autora “descrição densa” refere-se ao desempenho etnográfico, que seria baseado em interpretação, ou seja, "não é apenas uma descrição minuciosa, mas uma leitura, uma interpretação”. (2008, p. 4)

Claro está que o enfoque no trabalho de Sandra Farias (2008) se dá em uma perspectiva antropológica do romance, em oposição ao que estamos tratando nesse artigo, cujo intuito é fazer uma leitura do aspecto literário. Contudo, acredita-se que esse aspecto denso presente na narrativa influencia o desenvolvimento literário do romance, tornando-o por vezes fragmentado.

Seria temerário afirmar a intenção do autor em construir descrições de crenças, hábitos e costumes da tribo mairum. Sabemos que Darcy Ribeiro (1976) quis mostrar “o índio real, de carne e osso e nervos e mente, enredado na sua cultura, como nós na nossa, mas capaz de pensamentos e sentimentos”. (RIBEIRO, 1997, p.514) Todavia, essa é uma obra literária e as intenções do autor são quase sempre sobrepujadas pela construção do texto narrativo.

Ainda assim, há que se ressaltar o enorme estudo etnográfico que possibilitou a escrita do romance. Assim como Gonçalves Dias e José de Alencar, as fontes etnográficas se fazem muito presentes a fim de aproximar o leitor do universo indígena construído ficcionalmente. Os 
escritores românticos se utilizavam demasiadamente de notas explicativa, com as quais esclareciam termos utilizados em suas obras. Na narrativa de Darcy Ribeiro (1976) não há notas explicativas, mas as informações antropológicas e a descrição densa comprometem, de certa forma, a fluidez da narrativa.

\section{Questões Identitárias: O índio e a identidade brasileira}

As questões internas e o conflito existencial pelo qual passa a personagem principal de Maíra, Isaías/Avá, são abordados de maneira mais ampla como um dos temas da narrativa. Como se a angústia identitária de Isaías/Avá fosse reflexo da agonizante condição segregada do índio na sociedade brasileira.

Ao longo da história e, principalmente, da literatura brasileira, a figura do índio foi tratada de forma maniqueísta. Os que aceitavam a colonização eram bons, os que não adquiriam uma postura europeizada eram ruins. Diversos foram os enfoques acerca da postura do índio, até que no romantismo o elemento indígena ganhasse destaque na formação da identidade nacional. Isso ocorreu porque, segundo Antonio Candido (2008): "Ser bom, literariamente, significava ser brasileiro; ser brasileiro significava incluir nas obras o que havia de específico do país, notadamente a paisagem e o aborígene. Por isso o Indianismo aparece como timbre supremo de brasilidade”. (2008, p. 178)

Não foi qualquer índio a figura eleita para ser o símbolo da pátria. Os índios que resistiam à assimilação da civilização foram postos de lado e criou-se a imagem de um ser passivo, completamente disposto a adquirir os costumes do agente europeu. Para Manuela Carneira da Cunha, somente o índio "virtualmente extinto ou supostamente assimilado que figura por excelência na imagem que o Brasil faz de si mesmo.” (2012, p. 62). A historiadora afirma ainda que "o índio do romantismo na literatura e na pintura (...) é o índio bom e, convenientemente, morto.” (2012, p. 62)

Claro está que no processo de consolidação de uma identidade nacional não se apresentam controvérsias. Dessa forma, a figura idealizada do índio foi constituída para embasar o passado orgulhoso de uma nação recém-criada: "Num país sem tradições, é compreensível que se tenha desenvolvido a ânsia de ter raízes, de aprofundar no passado a própria realidade, a fim de demonstrar a mesma dignidade histórica dos velhos países”. (CANDIDO, 2008, p.179)

Dessa forma, o elemento indígena se confunde com a identidade brasileira. No romance de Darcy Ribeiro (1976) é a identidade do índio que está em xeque. Se o movimento de criação do ideário nacional saciou sua “ânsia de ter raízes” através do elemento indígena, Isaías/Avá se angustia justamente porque “tenho raiz demais. Estou cheio!” ( $M$, p. 61). 
Alma também reconhece que o motivo de todo o conflito de Isaías/ Avá se deve a ele não saber a que mundo pertence. Ela afirma: "Isaías sofre de ambiguidade essencial” ( $M$, p. 370) Assim sendo, a miscigenação que foi exaltada no movimento modernista, cantada em Martim Cererê, por exemplo, também é questionada pela figura do índio caído, representada por Isaías/Avá. Ao invés de reconhecer em si uma identidade brasileira multifacetada, Isaías/Avá se sente perdido, pois como afirma Alma: “É muito ruim para uma pessoa ser apenas um pouco alguma coisa. Fica pendurado entre dois mundos, como esse pobre Isaías, ou como eu mesma.” (M, p. 352)

A questão da identidade brasileira é trabalhada por Darcy Ribeiro (1995) em seu livro O Povo Brasileiro - A Formação e O Sentido do Brasil. Nele, o antropólogo chega a afirmar que nunca houve no Brasil um conceito de povo que pudesse englobar todos os trabalhadores. Havia uma sociedade que "era, de fato, um mero conglomerado de gentes multiétnicas, oriundas da Europa, da África ou nativos daqui mesmo, ativadas pela mais intensa mestiçagem.” (RIBEIRO, 1995, p.448)

Para Darcy, isso aconteceu porque a mestiçagem resultou na perda de particularidade de cada etnia:

Despojados de sua identidade, se veem condenados a inventar uma nova etnicidade englobadora de todos eles. Assim é que se foi fundindo uma crescente massa humana que perdera a cara: eram ex-índios desindianizados, e sobretudo mestiços, mulheres negras e índias, muitíssimas, com uns pouquíssimos brancos europeus que nelas se multiplicaram prodigiosamente. (RIBEIRO, 1995, p. 448)

Essa interpretação reflete uma visão do papel da "mistura de raças" na identidade do povo brasileiro segundo a qual o brasileiro é o resultado das qualidades de índios, negros e portugueses, como vemos na obra citada de Cassiano Ricardo. Porém, nesse sentido destacado por Darcy, a aglomeração das etnias não resulta em um povo, mas sim em uma "massa humana que perdera a cara”.

O índio cantado como símbolo de identidade nacional na literatura romântica, é em Maíra um índio em crise de identidade. O enfoque narrativo do ponto de vista do índio permite que se explore a visão da civilização como ameaça à identidade indígena.

Isaías/Avá é um índio que sofreu processo de “desindianização”, mas, em alguns momentos de seu discurso, revela que é preciso se manter índio e resistir aos avanços da civilização:

Este é o único mandado de Deus que me comove todo: o de que cada povo permaneça ele mesmo, com a cara que Ele lhe deu, custe o que custar. Nosso dever, nossa sina, não sei, é resistir, como resistem os judeus, os 
ciganos, os bascos e tantos mais. Todos inviáveis, mas presentes. Cada um de nós, povos inviáveis, é uma face de Deus. Com sua língua própria que muda no tempo, mas que só muda dentro de uma pauta. Com seus costumes e modos peculiares, que também mudam, mas mudam por igual, dentro do seu próprio espírito. ( $M$, p. 33)

Mesmo esse discurso de resistência reconhece que, na forma de organização da sociedade brasileira, o índio faz parte de um “povo inviável”, destinado a viver numa reserva estabelecida pela civilização. Assim sendo, o índio não tem lugar no mundo civilizado e o mundo civilizado busca, cada vez mais, “desindianizar” o índio, como afirma o próprio Isaías: "Cada um que sai da aldeia vai ser como eu, ou seja, coisa nenhuma. Os que ficarem lá herdarão a amargura de serem índios”. ( $M$, p.310)

A visão pessimista do destino do índio também é trabalhada de maneira simbólica. Maíra, o deus da tribo mairum, possuía um irmão gêmeo, chamado Micura. Ao longo da narrativa conhecemos a cosmogonia que cerca essas duas figuras. Alma, a branca que vai viver na tribo mairum, é encontrada morta ao dar à luz dois meninos gêmeos, filhos de índios, que também morreram no parto. Simbolicamente, podemos interpretar esse fato como mais um indício da conciliação impossível entre mundo civilizado e índios.

Por fim, é importante ressaltar que a narrativa dos conflitos identitários e existenciais de Isaías é dividida pelo narrador em quatro partes, cujos títulos remetem ao ato litúrgico da missa católica (Antífona / Homilia / Cânon / Corpus). Dessa forma, ao mesmo tempo em que a estrutura do livro faz menção à religião católica, o percurso da personagem principal é em direção à cultura indígena, culminando com o abandono da batina. Esse contraponto entre a estrutura da narrativa e o caminho da personagem refletem, de certa forma, a crise de identidade pela qual passa Isaías/Avá, um índio que busca entender o que significa ser índio e ser brasileiro.

\section{Considerações Finais}

Ao longo desse trabalho, vimos que diversas perspectivas permeiam as manifestações literárias que abordam o tema do índio ao longo da literatura brasileira. Apesar de o índio ser figura central do movimento romântico, as representações acerca do elemento indígena permeiam toda a história da literatura brasileira.

Em Maíra, a personagem central é um índio caído, uma figura problematizada por questões interiores e subjetivas na tentativa de entender o que é ser índio na sociedade brasileira do final do século XX. A narrativa, permeada de descrições sobre hábitos e cultura indígena, revela não só a influência dos estudos antropológicos de Darcy Ribeiro, mas indica a postura adotada pelo narrador. 
Claramente, percebe-se que o narrador de Maíra toma partido do índio. A grande crítica do romance é contra o processo de civilização predatório, que não respeita as individualidades indígenas. Com isso, é também criticada a política indianista, desempenhada pela FUNAI, que não fosse voltada para os interesses do índio e não valorizava sua cultura.

Finalmente, pudemos perceber que a relação entre a representação indígena e o discurso da identidade nacional foi muito presente na literatura brasileira. Em Maíra, há uma abordagem do ponto de vista do índio, que questiona sua identidade e a possibilidade de se integrar na sociedade em geral.

\section{Referências}

BASTOS, Alcmeno. O Índio Antes do Indianismo. Rio de Janeiro: 7Letras/Faperj, 2011.

BOSI, Alfredo. História Concisa da Literatura Brasileira. 36ª ed. São Paulo: Cultrix, 1994.

CANDIDO, Antonio. Literatura e sociedade. $10^{\mathrm{a}}$ ed. Rio de Janeiro: Ouro Sobre Azul, 2008.

CUNHA, Manuela Carneiro da. Índios no Brasil: história, direitos e cidadania. São Paulo: Claro Enigma, 2012.

FARIAS, Sandra Martins. Maíra - Narrativa sobre o Mal entre os Mairuns. In: 26a REUNIÃO BRASILEIRA DE ANTROPOLOGIA: DESIGUALDADE NA MODERNIDADE, Porto Seguro. Anais... Porto Seguro, 2008.

PERRONE-MOISÉS, Leyla. Falência da Crítica. São Paulo: Editora Perspectiva, 1973.

RIBEIRO, Darcy. Maíra. Rio de Janeiro: Civilização Brasileira, 1976.

RIBEIRO, Darcy. O Povo Brasileiro - O Formação e o Sentido do Brasil. São Paulo: Cia das Letras, 1995.

RIBEIRO, Darcy. Confissões. São Paulo: Cia das Letras, 1997.

Data de submissão: 08/12/2013

Data de aprovação: 06/04/2014 